\title{
Impact of great gerbils (Rhombomys opimus) on desert plant communities
}

\author{
XU Wenxuan' ${ }^{1}$, LIU Wei ${ }^{2}$, YANG Weikang ${ }^{1 *}$, WANG Muyang ${ }^{1}$, XU Feng $^{1}$, David BLANK ${ }^{1}$ \\ ${ }^{1}$ Key laboratory of Biogeography and Bioresources in Arid Lands, Xinjiang Institute of Ecology and Geography, Chinese \\ Academy of Sciences, Urumqi 830011, China; \\ ${ }^{2}$ College of Life Science and Technology, Southwest University for Nationalities, Chengdu 610043, China
}

\begin{abstract}
Great gerbil (Rhombomys opimus) colonies, with bare soil and herbaceous plants, are conspicuous to the background environment throughout their range area. In order to quantify the engineer role of great gerbils, we investigated the plant communities of 20 active colonies in the Junggar Basin, Xinjiang, China. In areas without disturbance, desert plant communities were dominated by the shrubs with low level species richness. In burrow areas and surrounding intermediate areas, which were disturbed by great gerbils, the shrubs were suppressed with the decrease of vegetation cover and aboveground biomass. As a result, "niche gaps" were created in disturbed areas and worked as a refuge for herbaceous annuals and perennials. So the existence of great gerbils increased the overall species richness of the desert. Furthermore, herbaceous annuals and perennials are the major food source for great gerbils in spring, indicating that great gerbils have a mutually beneficial relationship with herbaceous plants.
\end{abstract}

Keywords: Rhombomys opimus; ecosystem engineer; species richness; mutually beneficial relationship

Citation: XU Wenxuan, LIU Wei, YANG Weikang, WANG Muyang, XU Feng, David BLANK. 2015. Impact of great gerbils (Rhombomys opimus) on desert plant communities. Journal of Arid Land, 7(6): 852-859. doi: 10.1007/s40333-015-0084-2

Fossorial rodents excavate extensive tunnels underground, which continuously deposit soil aboveground (Reichman and Smith, 1985) and affect the heterogeneity and availability of soil nutrients (Huntly and Inouye, 1988; Desmet and Cowling, 1999; Willot et al., 2000). Jones et al. (1994) defined these animals as ecosystem engineers, because they are able to modify resource distribution and/or create habitat for other species. These ecosystem engineering effects have been widely and intensively studied throughout the world. Coupled with aboveground and underground foraging, fossorial rodents, such as kangaroo rats (Dipodomys spectabilis) (Guo, 1996), plateau pikas (Ochotona curzoniae) (Smith and Foggin, 1999; Zhang et al., 2003), pocket gophers (Thomomys bottae) (Reichman and Seabloom, 2002), prairie dogs (Cynomys ludovicianus) (van Nimwegen et al., 2008) and European rabbits (Oryctolagus cuniculus) (Gálvez-
Bravo et al., 2011), have significant effects on the structure, composition and productivity of plant communities. Great gerbils (Rhombomys opimus) are a diurnal, fossorial and colonial rodent species that are widely distributed in Central Asia. Allegedly, these animals are in direct competition with livestock since they destroy the vegetation within and around their colonies (Wang and Yang, 1983) through biting the main roots and therefore causing the die-off of plants (Taoboer et al., 2008). In addition, great gerbils are also the carriers of diseases such as plague and Leishmaniasis (Wilschut et al., 2013). Therefore, great gerbils have been recognized as a pest species.

Nevertheless, great gerbils act as ecosystem engineers in Central Asia. Great gerbils alter the soil conditions through their excavation activities. The food hoarded in great gerbil burrows are also helpful for the growth of microbes, especially for fungi (Jiang

"Corresponding author: YANG Weikang (E-mail: yangwk@ms.xjb.ac.cn) Received 2015-01-27; revised 2015-04-30; accepted 2015-05-13

(C) Xinjiang Institute of Ecology and Geography, Chinese Academy of Sciences, Science Press and Springer-Verlag Berlin Heidelberg 2015 
et al., 2007), which in turn can accelerate the decomposition of the soil organic matter (Schlesinger et al., 1990). So, it is clear that great gerbils do improve the soil fertility conditions (Xu et al., 2012). Moreover, great gerbils are an important prey species for many wild carnivores and birds; their burrows are used by many small animals such as other gerbil species, jerboas, hamsters, shrews, birds, toads, hedgehogs, snakes, lizards and numerous species of arthropoda (Mokrousov, 1978).

Yet, as central foragers like the kangaroo rats (Guo, 1996) and European rabbits (Gálvez-Bravo et al., 2011), great gerbils have created large, distinctive and conspicuous colonies against their environmental background by burrowing and mound building (Mokrousov, 1978), which can even be viewed in satellite images (Wilschut et al., 2013). While little is known about the relationship between activities of great gerbils and the plant communities in Central Asia, there are only 2 studies reported the significant differences on plant community structures between the colonies and the undisturbed areas (Yang et al., 2006, 2009). However, the mechanism and the natural role of great gerbils as agents of vegetation disturbance has not yet been well discussed. Based on the above findings, in this paper, we explored the mechanism of great gerbil disturbance on the desert plant communities and elucidated the role of this species in Junggar Basin ecosystem. The aims of this paper were: (1) to understand how the plant community changes from the center of the great gerbils' colonies to their outer boundaries; and (2) to explain the engineering role of great gerbils on maintaining the plant species richness in the study area.

\section{Materials and methods}

\subsection{Study area}

The study area lies on the southern edge of the Gurbantunggut Desert $\left(44^{\circ} 31^{\prime}-44^{\circ} 33^{\prime} \mathrm{N}, 88^{\circ} 05^{\prime}-88^{\circ} 07^{\prime} \mathrm{E}\right)$ in the Junggar Basin, Xinjiang, China. The desert is characterized by massive, dense sand dunes, with about $80 \%$ of these dunes being stabilized or semi-stabilized by desert vegetation (Wang et al., 2005). The climate of the desert is characterized by temperate continental, with an annual mean temperature of $6-10^{\circ} \mathrm{C}$, mean annual precipitation of $150 \mathrm{~mm}$ and potential annual evaporation of above $2,000 \mathrm{~mm}$. There is a consistent $20-\mathrm{cm}$ deep snow cover in winter and the precipitation falling in April to July accounts for $47.6 \%$ of the annual amount (Wang et al., 2005).

Haloxylon persicum is the dominant species of the desert, with a vegetation cover of less than $30 \%$, and mainly appears on the upper parts of the sand dunes, while the interdune areas are mainly covered by the dwarf Ephedra przewalskii shrubs (Wang et al., 2005). Herbaceous perennials and annuals are widespread under the shrub, which include Allium pallasii, Gagea nigra, Carex physodes, Erodium oxyrrhynchum, Nonea caspica, Tragopogon sabulosus, and Erysimum cheiranthoides etc. Soil crusts are well developed in interdune areas under the vegetation and are heavily dominated by cyanobacterium Microcoleus vaginatus with occasional patches of lichen and moss (Zhang et al., 2006).

Small rodents, such as Meriones meridianus, Meriones tamariscinus, Meriones erythrourus, Dipus sagitta, Allactaga sibirica, etc., are very abundant in this desert. Great gerbils usually establish their colonies at the bottoms of dunes or in interdune areas with the sizes ranged from $25-40 \mathrm{~m}$ in diameter.

\subsection{Sampling}

Field work was initiated from 15-25 May 2011, the spring of the year, when the snowmelt and rainfall promoted the growth of annual plants, and the richness of plant species reached the highest level. This time of a year was the breeding season for great gerbils and they were most active. For our study, 20 active colonies were selected for vegetation sampling. The colonies were very distinctive for the absence of vegetation and ranged from $360-728 \mathrm{~m}^{2}$ with an inter-colony distance greater than $80 \mathrm{~m}$. Colonies were determined as being in active when fresh food scraps, feces and excavated soils appeared near burrow entrances. Because the number of great gerbils strongly correlated with the number of entrances (Wang et al., 1998), the density of entrances can be used to indicate the disturbance level (Mulder and Keall, 2001).

Radiating out from each colony, 3 plots with a size of $10 \mathrm{~m} \times 10 \mathrm{~m}$ each were sampled respectively in three areas, the burrow area, intermediate area and undisturbed control area along the disturbance gradient from burrow center to undisturbed control area (Fig. 1). The directions of sample plots that radiated from cen- 
ter to outside were oriented randomly. Burrow areas were characterized by frequent, unobstructed entrances to burrows with predominantly bare ground; intermediate areas were defined as transitional areas surrounding the burrows that contained few entrances with an intermediate amount of bare ground; and the outside control areas were dominated by shrubs without burrow entrance.

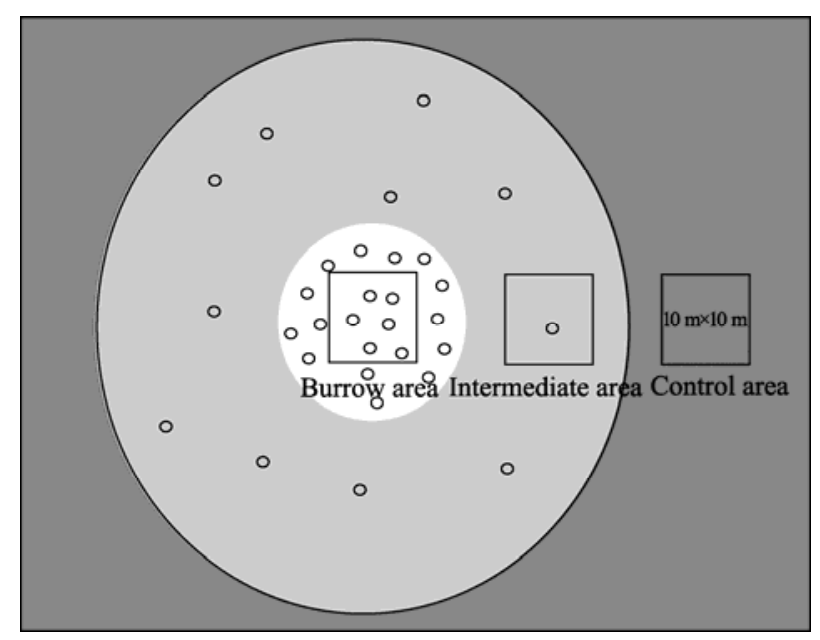

Fig. 1 Schematic view of great gerbil colony and the vegetation sampling design

The number of burrow entrances, number of plant species, individual shrubs and plant covers were recorded and measured in each plot. The locations of all plots were recorded with a GPS (Magellan Explorist 500). Within each plot, three small quadrats $(1 \mathrm{~m} \times 1 \mathrm{~m})$ were randomly placed; the species and number of individual plants were recorded. The percentage of an individual species cover refers to the measure of each herbaceous plant species and the total cover refers to the equivalent estimates for all species together. The aboveground biomass was estimated by clipping all plants in the three randomly chosen sampling quadrants $(1 \mathrm{~m} \times 1 \mathrm{~m})$ within the plot and then all clippings were sorted, dried at $60^{\circ} \mathrm{C}$ for $48 \mathrm{~h}$, and weighed.

\subsection{Data analysis}

Data were first checked for normal distribution prior to analysis by using the Kolmogorov-Smirnov $\mathrm{Z}$ test. For normal distribution data, One-way ANOVA analysis was used for measuring the differences of plant community parameters in burrow areas, intermediate areas and control areas; for non-normal distribution data, the Kruskal-Wallis test were used. Canonical discriminant analysis (CDA) was used to describe the changes of the plant communities among burrow areas, intermediate areas and control areas. Indicators used for CDA included the species richness, cover and aboveground biomass of shrubs, herbaceous perennials and annuals. Pearson correlation analysis (normal distribution) or Spearman correlation analysis (non-normal distribution) was used to identify disturbance level linking to community structure in terms of species richness, cover and aboveground biomass. All statistical analyses were performed using SPSS 20.0 (IBM Corp, Armonk, NY).

\section{Results}

There were significant differences among plant communities in burrow areas, intermediate areas and control areas $(\mathrm{CDA}, P<0.01)$ (Fig. 2). Function 1 represents a gradient of disturbance intensity and Function 2 represents the differences of intermediate areas from burrow areas and control areas. The two canonical functions together explained $100 \%$ of the differences. Shrubs, herbaceous perennials and annuals had the highest cover in the control, intermediate and burrow areas, respectively (Table 1). Influenced by the great gerbils' activities, the vegetation cover significantly decreased in intermediate areas (Mann-Whitney $U$ test, $Z=5.32, \quad P<0.01)$ with the shrub cover declining (Mann-Whitney $U$ test, $Z=5.41, P<0.01$ ) (Pearson correlation, $R s=0.95, P<0.01)$. The burrow areas were very distinctive when the vegetation cover was less than $5 \%$ (Table 1).

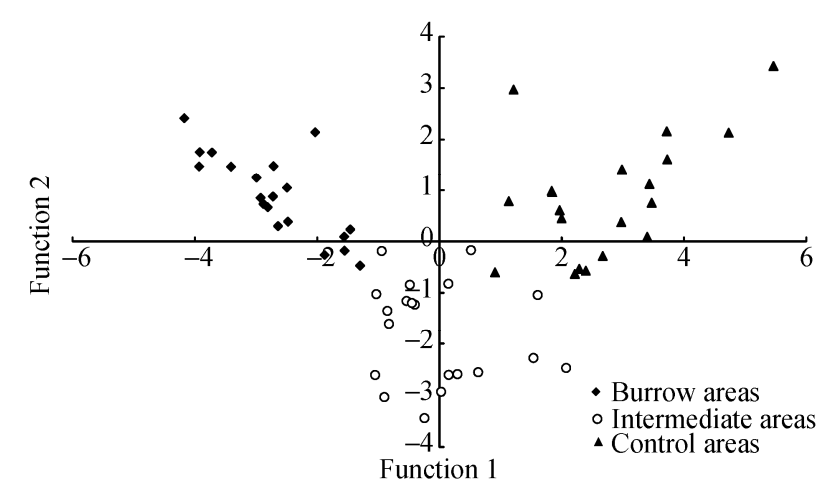

Fig. 2 Canonical discriminant analysis (CDA) showing separation of plant communities in three areas. The two canonical functions accounted for $100 \%$ (75.8\% and $24.2 \%$ for Function 1 and Function 2, respectively) of total variation. 
Table 1 The comparison of percent cover and density of plant species in different areas

\begin{tabular}{|c|c|c|c|c|c|c|c|c|}
\hline \multirow{2}{*}{ Vascular plant species } & \multicolumn{4}{|c|}{ Cover $(\%)$} & \multicolumn{4}{|c|}{ Density (individuals $/ \mathrm{m}^{2}$ ) } \\
\hline & Burrow & Intermediate & Control & $F / \chi^{2}$ & Burrow & Intermediate & Control & $F / \chi^{2}$ \\
\hline Shrubs & $0.48 \pm 0.16$ & $1.78 \pm 0.34$ & $11.90 \pm 1.35$ & $59.62^{* *}$ & $0.10 \pm 0.03$ & $0.25 \pm 0.05$ & $1.52 \pm 0.44$ & $9.37^{* *}$ \\
\hline Haloxylon persicum & - & - & + & $2.00^{\text {ns }}$ & - & - & + & $2.00^{\text {ns }}$ \\
\hline Kochia prostrata & + & + & - & $6.93^{\#}$ & $0.01 \pm 0.01$ & + & - & $5.36^{\text {ns }}$ \\
\hline Artemisia songarica & $0.12 \pm 0.06$ & $0.14 \pm 0.09$ & - & $10.27^{\#}$ & $0.02 \pm 0.01$ & $0.01 \pm 0.00$ & - & $13.95^{\# \#}$ \\
\hline Seriphidium santolinum & $0.12 \pm 0.10$ & $0.29 \pm 0.13$ & $0.20 \pm 0.07$ & $1.78^{\mathrm{ns}}$ & $0.03 \pm 0.01$ & $0.04 \pm 0.01$ & $0.05 \pm 0.02$ & $0.74^{\mathrm{ns}}$ \\
\hline Calligonum mongolicum & $0.13 \pm 0.06$ & $0.30 \pm 0.10$ & $0.22 \pm 0.10$ & $0.99^{\text {ns }}$ & + & $0.01 \pm 0.00$ & + & $0.95^{\text {ns }}$ \\
\hline Ephedra przewalskii & $0.11 \pm 0.08$ & $1.06 \pm 0.35$ & $11.47 \pm 1.37$ & $39.66^{\# \#}$ & $0.04 \pm 0.03$ & $0.20 \pm 0.05$ & $1.47 \pm 0.43$ & $41.31^{\# \#}$ \\
\hline Perennials & $0.33 \pm 0.06$ & $1.04 \pm 0.18$ & $0.66 \pm 0.12$ & $7.66^{* *}$ & $24.76 \pm 5.39$ & $85.36 \pm 14.74$ & $54.41 \pm 7.95$ & $8.90^{* *}$ \\
\hline Gagea nigra & + & + & + & $6.65^{\#}$ & $0.01 \pm 0.00$ & $0.02 \pm 0.01$ & + & $5.93^{\text {ns }}$ \\
\hline Allium pallasii & + & + & + & $24.32^{\# \#}$ & + & $0.01 \pm 0.00$ & $0.04 \pm 0.01$ & $25.52^{\# \#}$ \\
\hline Eremurus inderiensis & $0.03 \pm 0.03$ & $0.11 \pm 0.11$ & $0.10 \pm 0.09$ & $1.93^{\text {ns }}$ & $0.01 \pm 0.00$ & $0.03 \pm 0.03$ & $0.02 \pm 0.02$ & $3.16^{\mathrm{ns}}$ \\
\hline Cousinia affinis & + & + & + & $2.53^{\text {ns }}$ & $0.01 \pm 0.00$ & + & + & $3.80^{\mathrm{ns}}$ \\
\hline Scorzonera pusilla & $0.03 \pm 0.02$ & $0.03 \pm 0.03$ & - & $8.69^{\#}$ & $0.08 \pm 0.03$ & $0.05 \pm 0.03$ & - & $13.02^{\# \#}$ \\
\hline Astragalus flexus & $0.01 \pm 0.01$ & $0.03 \pm 0.02$ & $0.01 \pm 0.01$ & $2.03^{\text {ns }}$ & + & + & + & $0.01^{\text {ns }}$ \\
\hline Silene olgianaca & + & - & - & $2.00^{\mathrm{ns}}$ & + & - & - & $2.00^{\mathrm{ns}}$ \\
\hline Carex physodes & $0.25 \pm 0.05$ & $0.87 \pm 0.15$ & $0.54 \pm 0.08$ & $0.89^{\text {ns }}$ & $24.65 \pm 5.37$ & $85.25 \pm 14.74$ & $54.35 \pm 7.95$ & $8.91^{\# \#}$ \\
\hline Annuals & $3.36 \pm 0.47$ & $2.51 \pm 0.50$ & $2.24 \pm 0.32$ & $1.77^{\mathrm{ns}}$ & $71.57 \pm 7.47$ & $60.90 \pm 14.69$ & $26.36 \pm 4.45$ & $5.75^{*}$ \\
\hline Salsola paulsenii & $0.01 \pm 0.00$ & + & + & $16.75^{\# \#}$ & $0.03 \pm 0.01$ & $0.25 \pm 0.25$ & $0.01 \pm 0.00$ & $12.85^{\# \#}$ \\
\hline Horaninowia ulicina & $0.04 \pm 0.02$ & + & + & $19.37^{\# \#}$ & $3.74 \pm 1.76$ & $0.04 \pm 0.03$ & + & $23.50^{\# \#}$ \\
\hline Corispermum lehmannianum & $0.05 \pm 0.01$ & + & - & $33.37^{\# \#}$ & $0.20 \pm 0.05$ & $0.01 \pm 0.00$ & - & $38.20^{\# \#}$ \\
\hline Ceratocarpus arenarius & $0.01 \pm 0.00$ & + & $0.01 \pm 0.00$ & $1.81^{\mathrm{ns}}$ & $0.04 \pm 0.01$ & $0.06 \pm 0.03$ & $0.14 \pm 0.04$ & $7.17^{\#}$ \\
\hline Atriplex dimorphostegia & + & - & - & $10.07^{\#}$ & $0.01 \pm 0.00$ & - & - & $15.51^{\# \#}$ \\
\hline Syrenia siliculosa & $0.01 \pm 0.00$ & - & + & $2.11^{\mathrm{ns}}$ & + & - & + & $2.11^{\mathrm{ns}}$ \\
\hline Malcolmia scorpioides & $0.05 \pm 0.04$ & $0.01 \pm 0.00$ & + & $16.11^{\#}$ & $0.23 \pm 0.19$ & $0.04 \pm 0.01$ & $0.01 \pm 0.00$ & $11.23^{\# \#}$ \\
\hline Tetracme quadricornis & $0.02 \pm 0.01$ & + & - & $13.13^{\#}$ & $0.07 \pm 0.04$ & $0.01 \pm 0.00$ & - & $19.94^{\# \#}$ \\
\hline Isatis violascens & $0.01 \pm 0.00$ & + & - & $12.49^{\# \#}$ & $0.04 \pm 0.01$ & + & - & $22.65^{\# \#}$ \\
\hline Isatis minima & $0.03 \pm 0.02$ & + & - & $7.20^{\#}$ & $0.04 \pm 0.03$ & + & - & $9.81^{\# \#}$ \\
\hline Alyssum linifolium & + & $0.11 \pm 0.05$ & $0.87 \pm 0.26$ & $33.99^{\#}$ & $0.03 \pm 0.02$ & $2.47 \pm 1.12$ & $12.90 \pm 4.01$ & $40.48^{\# \#}$ \\
\hline Hyalea pulchella & $0.19 \pm 0.06$ & $0.08 \pm 0.01$ & $0.16 \pm 0.05$ & $0.52^{\mathrm{ns}}$ & $0.19 \pm 0.04$ & $0.19 \pm 0.04$ & $0.25 \pm 0.06$ & $1.64^{\mathrm{ns}}$ \\
\hline Cancrinia discoidea & + & + & + & $0.38^{\mathrm{ns}}$ & + & $0.01 \pm 0.01$ & $0.01 \pm 0.01$ & $1.19^{\mathrm{ns}}$ \\
\hline Amberboa turanica & $0.04 \pm 0.01$ & $0.02 \pm 0.01$ & + & $6.47^{\#}$ & $0.06 \pm 0.02$ & $0.07 \pm 0.05$ & $0.01 \pm 0.01$ & $6.49^{\text {ns }}$ \\
\hline Epilasia hemilasia & + & + & + & $2.81^{\mathrm{ns}}$ & $0.01 \pm 0.00$ & $0.01 \pm 0.01$ & + & $3.50^{\mathrm{ns}}$ \\
\hline Crepis sp. & + & + & + & $18.86^{\# \#}$ & $0.02 \pm 0.00$ & $0.01 \pm 0.01$ & + & $20.41^{\# \#}$ \\
\hline Lactuca undulata & + & + & $0.01 \pm 0.00$ & $8.76^{\#}$ & $0.01 \pm 0.01$ & $0.01 \pm 0.01$ & $0.05 \pm 0.01$ & $13.93^{\# \#}$ \\
\hline Lappula semiglabra & $0.08 \pm 0.03$ & + & + & $24.74^{\#}$ & $0.07 \pm 0.02$ & $0.01 \pm 0.01$ & $0.01 \pm 0.01$ & $22.19^{\# \#}$ \\
\hline Lepechiniella lasiocarpa & $0.02 \pm 0.02$ & + & + & $1.15^{\mathrm{ns}}$ & $0.01 \pm 0.00$ & + & $0.02 \pm 0.02$ & $0.47^{\mathrm{ns}}$ \\
\hline Arnebia decumbens & $0.13 \pm 0.04$ & + & + & $28.06^{\#}$ & $0.25 \pm 0.07$ & $0.02 \pm 0.01$ & + & $31.56^{\# \#}$ \\
\hline Nonea caspica & $0.06 \pm 0.02$ & $0.01 \pm 0.00$ & + & $9.42^{* *}$ & $0.05 \pm 0.01$ & $0.03 \pm 0.01$ & $0.02 \pm 0.00$ & $4.71^{*}$ \\
\hline Astragalus arpilobus & $0.08 \pm 0.05$ & $0.02 \pm 0.01$ & + & $24.02^{\#}$ & $0.44 \pm 0.35$ & $0.06 \pm 0.02$ & $0.02 \pm 0.01$ & $21.11^{\# \#}$ \\
\hline Trigonella arcuata & $0.02 \pm 0.01$ & $0.04 \pm 0.02$ & $0.02 \pm 0.01$ & $0.16^{\mathrm{ns}}$ & $0.10 \pm 0.05$ & $0.21 \pm 0.06$ & $0.15 \pm 0.05$ & $0.59^{\mathrm{ns}}$ \\
\hline Hypecoum parviflorum & $0.06 \pm 0.04$ & $0.03 \pm 0.02$ & - & $29.66^{\# \#}$ & $0.05 \pm 0.01$ & $0.03 \pm 0.02$ & - & $32.17^{\# \#}$ \\
\hline Erodium oxyrrhynchum & $0.79 \pm 0.25$ & $0.93 \pm 0.29$ & $1.05 \pm 0.28$ & $0.31^{\mathrm{ns}}$ & $5.38 \pm 1.69$ & $4.81 \pm 1.70$ & $7.39 \pm 1.92$ & $4.92^{\mathrm{ns}}$ \\
\hline Euphorbia turczaninowii & $0.11 \pm 0.06$ & $0.01 \pm 0.01$ & + & $29.73^{\#}$ & $1.02 \pm 0.76$ & $0.12 \pm 0.10$ & $0.01 \pm 0.00$ & $25.79^{\# \#}$ \\
\hline Plantago minuta & + & + & + & $2.17^{\mathrm{ns}}$ & $0.01 \pm 0.01$ & $0.01 \pm 0.01$ & $0.01 \pm 0.00$ & $2.11^{\mathrm{ns}}$ \\
\hline Nepeta micrantha & $0.13 \pm 0.04$ & $0.07 \pm 0.05$ & $0.02 \pm 0.01$ & $21.62^{\# \#}$ & $1.93 \pm 0.97$ & $0.89 \pm 0.64$ & $1.58 \pm 0.91$ & $7.33^{\#}$ \\
\hline Schismus arabicus & $1.42 \pm 0.34$ & $1.16 \pm 0.36$ & $0.09 \pm 0.04$ & $23.46^{\# \#}$ & $57.52 \pm 6.82$ & $51.49 \pm 13.94$ & $3.75 \pm 1.86$ & $25.15^{\# \#}$ \\
\hline Eremopyrum orientale & $0.01 \pm 0.00$ & $0.01 \pm 0.00$ & + & $0.36^{\mathrm{ns}}$ & $0.02 \pm 0.01$ & $0.04 \pm 0.02$ & $0.01 \pm 0.00$ & $0.77^{\mathrm{ns}}$ \\
\hline Total & $4.17 \pm 0.47$ & $5.33 \pm 0.52$ & $14.80 \pm 1.33$ & $45.16^{* *}$ & $96.43 \pm 8.23$ & $146.51 \pm 20.09$ & $82.30 \pm 9.45$ & $6.09^{* *}$ \\
\hline
\end{tabular}

Note: - , not found in the plots; + , the value less than $0.01 ;{ }^{* *}, P<0.01$ by one way ANOVA; ${ }^{*}, P<0.05$ by one way ANOVA; ${ }^{\#}, P<0.01$ by Kruskal-Wallis test; ${ }^{\#}$, $P<0.05$ by Kruskal-Wallis test; ${ }^{\text {ns }}$, no significant difference. 
A total of 44 vascular plant species were recorded in these three areas, and 43 species were recorded in burrow plots, 41 species in intermediate plots, and 37 species in control plots (Table 1). The annuals flour- ished in burrow areas, with the highest percent cover, density, species richness and above-ground biomass (Tables 1 and 2), especially the annual grass Schismus arabicus, reached its highest percent cover and density

Table 2 The comparison of species richness and aboveground biomass in three areas

\begin{tabular}{|c|c|c|c|c|c|c|c|}
\hline \multicolumn{4}{|c|}{ Species richness } & \multicolumn{4}{|c|}{ Aboveground biomass $\left(\mathrm{g} / \mathrm{m}^{2}\right)$} \\
\hline Burrow & Intermediate & Control & $F$ & Burrow & Intermediate & Control & $F / \chi^{2}$ \\
\hline $1.85 \pm 0.25$ & $1.75 \pm 0.16$ & $1.80 \pm 0.16$ & $0.07^{\mathrm{ns}}$ & $2.86 \pm 1.40$ & $9.71 \pm 2.41$ & $35.07 \pm 3.46$ & $38.14^{\# \#}$ \\
\hline $2.70 \pm 0.27$ & $2.55 \pm 0.22$ & $2.30 \pm 0.21$ & $0.74^{\mathrm{ns}}$ & $2.13 \pm 0.52$ & $7.94 \pm 1.09$ & $5.46 \pm 0.77$ & $12.44^{* *}$ \\
\hline $20.00 \pm 0.88$ & $13.40 \pm 0.64$ & $11.10 \pm 0.51$ & $44.19^{* *}$ & $9.75 \pm 0.79$ & $5.02 \pm 0.62$ & $4.14 \pm 0.66$ & $25.11^{\# \#}$ \\
\hline $24.55 \pm 1.21$ & $17.70 \pm 0.74$ & $15.20 \pm 0.60$ & $29.41^{* *}$ & $14.73 \pm 1.45$ & $22.67 \pm 2.71$ & $44.66 \pm 3.80$ & $30.21^{* *}$ \\
\hline
\end{tabular}

Note: ${ }^{* *}, P<0.01$ by one way ANOVA; ${ }^{\#}, P<0.01$ by Kruskal-Wallis test; ${ }^{\text {ns }}$, no significant difference.

(Table 1). Herbaceous perennials thrived in the intermediate areas adjacent to the burrow areas with the highest percent cover, density and above-ground biomass (Tables 1 and 2), especially Carex physodes reached its highest percent cover and density (Table 1). Shrubs dominate the community with highest percent cover, above-ground biomass and density in undisturbed control areas (Tables 1 and 2), especially $E$. przewalskii reached its highest percent cover and density (Table 1).

Total plant species richness decreased significantly from the burrow areas to undisturbed control areas due to the decrease of the annuals species (Table 2). The pattern of total species richness was notably driven by a higher annual species number (Pearson Correlation, $R s=0.97, P<0.01)$; the shrubs and perennials species richness did not show differences in these three areas (Table 2). Analyzed by the Pearson correlation test, the total species richness had a significant and positive correlation with the disturbance level $(R s=0.65$, $P<0.01)$, especially the species richness $(R s=0.71$, $P<0.01$ ) (Fig. 3) and the aboveground biomass $(R s=0.64, P<0.01)$ of the annuals.

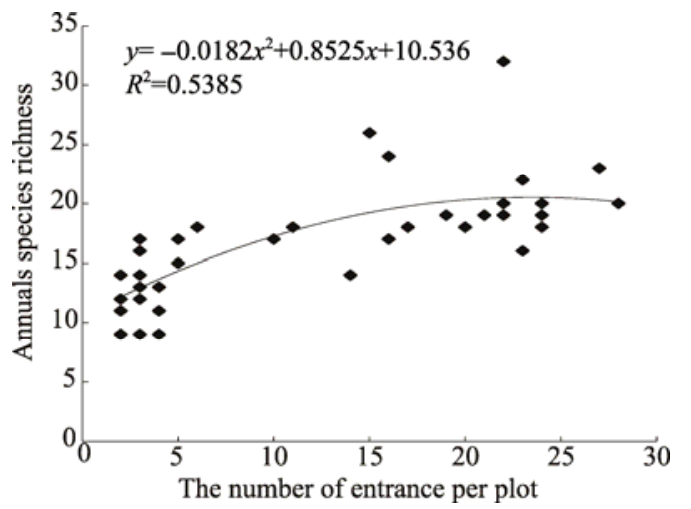

Fig. 3 Relationship between great gerbil disturbance level and annuals plant species richness

\section{Discussion}

Compared with communities in undisturbed control areas, distinct annual communities appeared in burrow areas and herbaceous perennial communities appeared the surrounding intermediate areas (Fig. 2; Table 1). Thus the disturbance of great gerbil affects the community structure and the disturbance effects not only occurred in burrow areas, albeit primarily, but also in intermediate areas. As a determining factor for the plant community (McIntire and Hik, 2005), such effects of the great gerbils on annuals, herbaceous perennials and shrubs were varied. Denslow (1985) suggested that the "disturbance frequency may have as strong a selective effect on species as do the physical characteristics of the habitat". We assumed that the different effects of great gerbil activities on annuals, herbaceous perennials and shrubs can be explained by different plant tolerances to the disturbances.

Benefiting from frequent disturbances, early successional annuals were the most successful growth forms on the disturbed soils in burrow areas. Burrow entrances likely act as seed traps for annuals for the regeneration process of the plants (Boekon et a1., 1998; James et al., 2009); the disruption of soil crusts by great gerbil activities likely facilitate the germination and establishment of annuals. With the increase of disturbance intensity, both aboveground biomass and species richness of annuals therefore increased (Table 2; Fig. 3) and the total species richness increased as well due to the increase of annual species richness (Pearson correlation, $R s=0.97, P<0.01$ ). The urine and feces of the great gerbils can raise the soil nutrition level near their burrows (Xu et al., 2012), the 
soil water content (Jiang et al., 2007) and the abundance of annual, particularly Schismus arabicus (Table 1).

Herbaceous perennials are more susceptible than annuals to the great gerbils' underground activities in burrow areas, because they are geophytes that propagate by means of buds below the soil surface. Since plant life history traits affect responses to disturbance (Grime, 1977; Huston and Smith, 1987), the competitiveness of herbaceous perennials is better than the early successional annuals in the intermediate areas where relatively lower disturbance levels occur. Thus, perennials, such as Carex physodes, were most successful in the intermediate areas with the highest cover and abundance value (Table 1).

Shrubs are foraged and hoarded specifically because they are the most important food source for great gerbils in autumn and winter (Iakovlev, 1969; Liu et al., 2012). During our survey, we found a large amount of fresh and dry shrub branches near burrow entrances, mostly E. przewalskii, which indicated that great gerbils consumed and stored a large amount of $E$. przewalskii as winter food (Liu et al., 2012). The gerbils' consumption or cutting of roots and the creation of air spaces (Taoboer et al., 2008) promoted root desiccation and the die-off of shrubs (Reichman and Smith, 1985). Since these plants dominated the plant community, the total ground cover and above-ground biomass decreased significantly with the decrease of the shrubs.

Species richness usually declined in shrub-dominated communities due to the asymmetric competition (Báez et al., 2013). In the study area, shrubs, especially $E$. przewalskii, dominated undisturbed plant communities. The key findings of this paper are that the great gerbils' disturbances increased the overall species richness of the plant community. According to the gap dynamics theory and the idea of the "regeneration niche" (Platt, 1975; Grubb, 1977; Denslow, 1985), great gerbils increased their habitat's heterogeneity by suppressing shrubs and creating small patches as "niche gaps" for herbaceous species that were usually excluded from shrub-dominated communities. In North America, this same phenomenon was also found in mounds of kangaroo rats (Mun and Whitford,
1990; Guo, 1996) and pocket gophers (Martinsen et al., 1990). With a higher plant species richness than other deserts in Central Asia (Zhang and Chen, 2002), the existence of the great gerbils is particularly important in the maintenance of floristic diversity and stability of Gurbantunggut Desert.

\section{Conclusion}

In study area, the relatively stable zonal vegetation community was dominated by the shrub species, and this study confirmed the negative effect of great gerbils on shrub plants. However, like a coin has two sides, the disturbance of great gerbil promoted the growth of annual and perennial plants that suppressed by the shrub plants in undisturbed areas. Therefore, the disturbance of great gerbils can provide ecological benefits in a stable ecosystem, but the population outbreak of great gerbils also can pose problems to the desert ecosystem.

Due to eupeptic characteristics like fine-texture and high solute cell content, herbaceous annuals and perennials were favored by great gerbils and comprised approximately $80 \%$ of their diet in spring (Liu et al., 2012). We observed that annuals and perennials flourished in areas where were mostly disturbed by great gerbils. Such forage patterns not only saved time and energy for great gerbils, but also reduced the predation risk from their natural enemies by foraging further from their burrows (Xu et al., 2013). Thus it was reasonable to assume that a mutually beneficial relationship exists between the great gerbils and herbaceous plants, which was also found in studies of pocket gophers (Stromberg and Griffin, 1996) and mole-voles (Microtus duodecimcostatus) (Gómez-García et al., 2004).

\section{Acknowledgements}

This study was granted by the National Basic Research Program of China (2014CB954204), the National Natural Science Foundation of China (30970476) and the Western Light Program of the Chinese Academy of Sciences (XBBS201309). We thank Dr. Scot FERGUSON, Prof. Barry PERRYMAN and Mrs. Patricia JOHNSTON for editing our manuscript, and Dr. LI Bang, Dr. ZHAI Wei, and Mr. JIN Shijie for helping with the field work. 


\section{References}

Báez S, Collins S L, Pockman W T, et al. 2013. Effects of experimental rainfall manipulations on Chihuahuan Desert grassland and shrubland plant communities. Oecologia, 172(4): 1117-1127.

Boekon B, Lipchin C, Gutterman Y, et al. 1998. Annual plant community responses to density of small-scale soil disturbances in the Negev Desert of Israel. Oecologia, 114(1): 106-117.

Denslow J S. 1985. Disturbance-mediated coexistence of species. In: Pickett S T A, White P S. The Ecology of Natural Disturbance and Patch Dynamics. New York: Academic Press, 307-323.

Desmet P G, Cowling R M. 1999. Patch creation by fossorial rodents: a key process in the revegetation of phytotoxic arid soils. Journal of Arid Environments, 43(1): 35-45.

Gálvez-Bravo L, López-Pintor A, Rebollo S, et al. 2011. European rabbit (Oryctolagus cuniculus) engineering effects promote plant heterogeneity in Mediterranean dehesa pastures. Journal of Arid Environments, 75(9): 779-786.

Gómez-García D, Azorín J, Giannoni S M, et al. 2004. How does $\mathrm{Me-}$ rendera Montana (L.) Lange (Liliaceae) benefit from being consumed by mole-voles? Plant Ecology, 172(2): 173-181.

Grime J P. 1977. Evidence for the existence of three primary strategies in plants and its relevance to ecological and evolutionary theory. The American Naturalist, 111(982): 1169-1194.

Grubb P J. 1977. The maintenance of species richness in plant communities: the importance of the regeneration niche. Biological Reviews, 52(1): 107-145.

Guo Q F. 1996. Effects of bannertail kangaroo rat mounds on small-scale plant community structure. Oecologia, 106(2): 247-256.

Huntly N, Inouye R. 1988. Pocket gophers in ecosystems: patterns and mechanisms. BioScience, 38(11): 786-793.

Huston M, Smith T. 1987. Plant succession: life history and competition. The American Naturalist, 130(2): 168-198.

Iakovlev M G. 1969. Some results of numbers counting of great gerbil on constant plots during many years. Report 1 . Settlements density of gerbils. In: Iakovlev M G. Material of Scientific Conference for Institutions of Black Death Research in Middle Asia and Kazakhstan. Alma-Ata: Academic Press, 169-175.

James A I, Eldridge D J, Hill B M. 2009. Foraging animals create fertile patches in an Australian desert shrubland. Ecography, 32(5): 723-732.

Jiang H P, Wu N, Yang W K. 2007. Effects of Rhombomys opimus on microbial quantity, soil moisture, content and soil nutrient content in a desert. Arid Zone Research, 24(2): 187-192. (in Chinese)

Jones C G, Lawton J H, Shachak M. 1994. Organisms as ecosystem engineers. Oikos, 69(3): 373-386.

Liu W, Xu W X, Yang W K, et al. 2012. Food habits of the great gerbil (Rhombomys opimus) in the Southern Gurbantunggut Desert, Xinjiang, China. Pakistan Journal of Zoology, 44(4): 931-936.

Martinsen G D, Cushman J H, Whitham T G. 1990. Impact of pocket gopher disturbance on plant species diversity in a shortgrass prairie community. Oecologia, 83(1): 132-138.

McIntire E J B, Hik D S. 2005. Influences of chronic and current season grazing by collared pikas on above-ground biomass and species richness in subarctic alpine meadows. Oecologia, 145(2): 288-296.
Mokrousov N Y. 1978. The great gerbil-Rhombomys opimus Lichtenstein, 1823. In: Sludsky A A. Mammals of Kazakhstan, vol. 3. Alma-Alta: Nauka Press, 64-115.

Mulder C P, Keall S N. 2001. Burrowing seabirds and reptiles: impacts on seeds, seedlings and soils in an island forest in New Zealand. Oecologia, 127(3): 350-360.

Mun H T, Whitford W G. 1990. Factors affecting annual plants assemblages on banner-tailed kangaroo rat mounds. Journal of Arid Environments, 18(2): 165-173.

Platt W J. 1975. The colonization and formation of equilibrium plant species associations on badger disturbances in a tall-grass prairie. Ecological Monographs, 45(3): 285-305.

Reichman O J, Smith S C. 1985. Impact of pocket gopher burrows on overlying vegetation. Journal of Mammalogy, 66(4): 720-725.

Reichman O J, Seabloom E W. 2002. The role of pocket gophers as subterranean ecosystem engineers. Trends in Ecology and Evolution, 17(1): 44-49.

Schlesinger W H, Reynolds J F, Cunningham G L, et al. 1990. Biological feedbacks in global desertification. Science, 247(4946): 1043-1048.

Smith A T, Foggin J M. 1999. The plateau pika (Ochotona curzoniae) is a keystone species for biodiversity on the Tibetan Plateau. Animal Conservation, 2(4): 235-240.

Stromberg M R, Griffin J R. 1996. Long-term patterns in coastal California grasslands in relation to cultivation, gophers, and grazing. Ecological Applications, 6(4): 1189-1211.

Taoboer, ZHAO T B, Qinggele, et al. 2008. Rat disaster in Tenggenaoer shrubs, Damao, Inner Mongolia. Journal of Inner Mongolia Forestry Science \& Technology, 34(4): 42-44. (in Chinese)

van Nimwegen R E, Kretzer J, Cully J F, Jr. 2008. Ecosystem engineering by a colonial mammal: how prairie dogs structure rodent communities. Ecology, 89(12): 3298-3305.

Wang S B, Sun Y Z, Zhao X C. 1998. The method for investigating population density of great gerbil Rhombomys opimus Licht. in the Zhungar desert. Endemic Diseases Bulletin, 13(1): 81-83. (in Chinese)

Wang S, Yang G. 1983. Rodent Fauna of Xinjiang. Urumqi: Xinjiang People's Publishing House, 136-142. (in Chinese)

Wang X Q, Wang T, Jiang J, et al. 2005. On the sand surface stability in the southern part of Gurbantünggüt Desert. Science in China Series D: Earth Sciences, 48(6): 778-785.

Willot S J, Miller A J, Incoll L D, et al. 2000. The contribution of rabbits (Oryctolagus cuniculus L.) to soil fertility in semi-arid Spain. Biology and Fertility of Soils, 31(5): 379-384.

Wilschut L I, Addink E A, Heesterbeek J A P, et al. 2013. Mapping the distribution of the main host for plague in a complex landscape in Kazakhstan: An object-based approach using SPOT-5 XS, Landsat 7 ETM+, SRTM and multiple Random Forests. International Journal of Applied Earth Observation and Geoinformation, 23: 81-94.

Xu F, Liu W, Qiao H H, et al. 2013. Relationships between vigilance, foraging and other behaviors of the great gerbil Rhombomys opimus. Arid Land Geography, 36(1): 118-124. (in Chinese)

Xu W X, Liu W, Yang W K, et al. 2012. Rhombomys opimus contribution to the "fertile island" effect of tamarisk mounds in Junggar Basin Ecological Research, 27(6): 775-781. 
Yang W K, Qiao J F, Jiang H P, et al. 2006. Impact of burrows of the great gerbil on small-scale plant community in Junggar Desert, China. Arid Land Geography, 29(2): 219-224. (in Chinese)

Yang W K, Jiang H P, Wang X Q, et al. 2009. Disturbance effects of Rhombomys opimus on desert plant community in Gurbantonggut Desert. Chinese Journal of Ecology, 28(10): 2020-2025. (in Chinese)

Zhang L Y, Chen C D. 2002. On the general characteristics of plant diversity of Gurbantunggut sandy desert. Acta Ecologica Sinica,
22(11): 1923-1932. (in Chinese)

Zhang Y M, Zhang Z B, Liu J K. 2003. Burrowing rodents as ecosystem engineers: the ecology and management of plateau zokors Myospalax fontanierii in alpine meadow ecosystems on the Tibetan Plateau. Mammal Review, 33(3-4): 284-294.

Zhang Y M, Wang H L, Wang X Q, et al. 2006. The microstructure of microbiotic crust and its influence on wind erosion for a sandy soil surface in the Gurbantunggut Desert of Northwestern China. Geoderma, 132(3-4): 441-449. 